\title{
Alaska Division of Geological and Geophysical Surveys
}

RAW-DATA FILE 2014-2

LIDAR DATA FOR UNALAKLEET, ALASKA, COLLECTED OCTOBER 27, 2005

by

Lauren E. Southerland and Nicole E.M. Kinsman

MARCH 2014

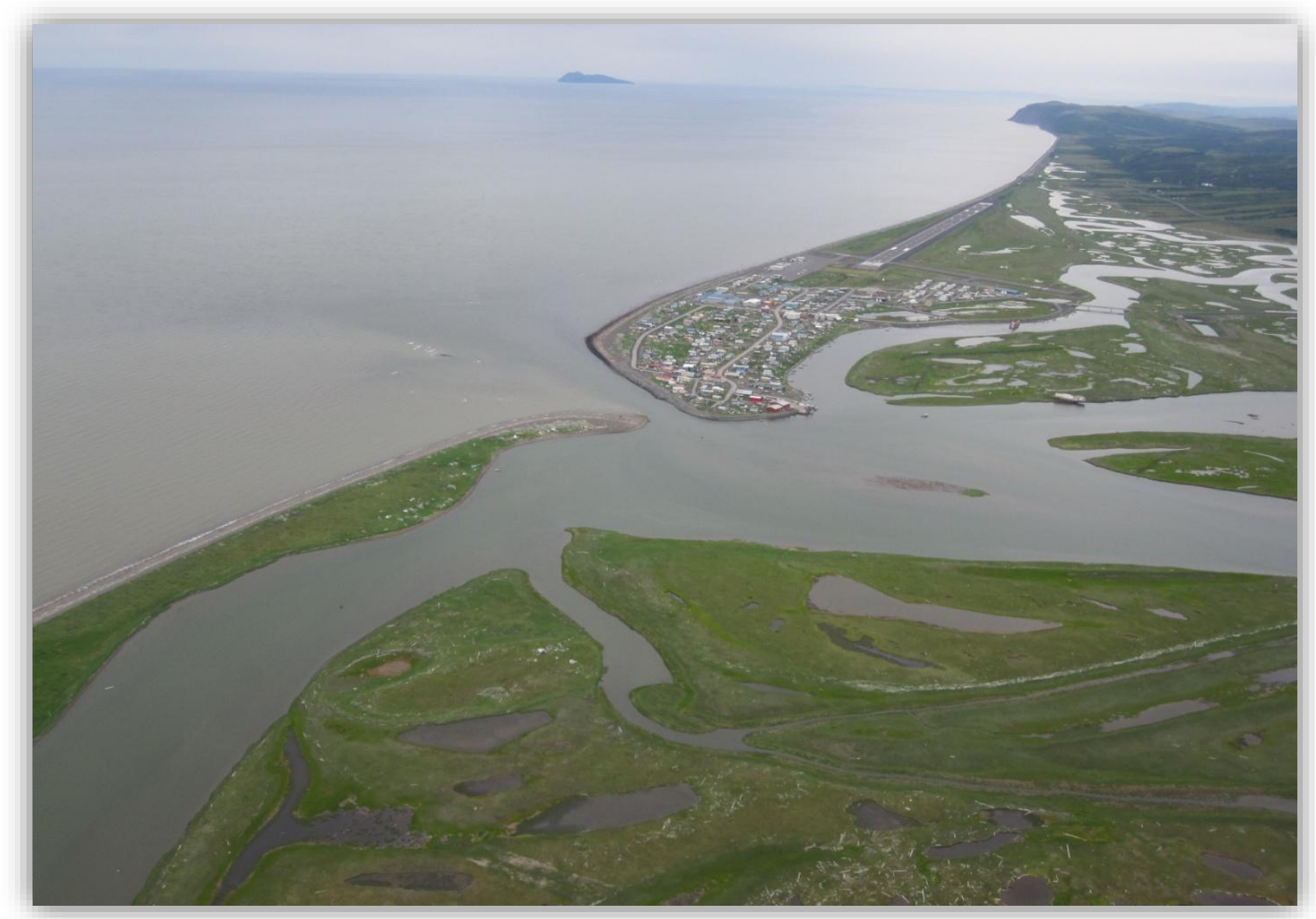

Oblique aerial photograph of Unalakleet in Norton Sound, Alaska, looking north across Unalakleet Inlet (photo by Nicole Kinsman, 2011).

Released by:

STATE OF ALASKA

DEPARTMENT OF NATURAL RESOURCES

Division of Geological \& Geophysical Surveys

3354 College Road, Fairbanks, Alaska 99709-3707

Email: dggspubs@alaska.gov

Website: www.dggs.alaska.gov 



\section{CONTENTS}

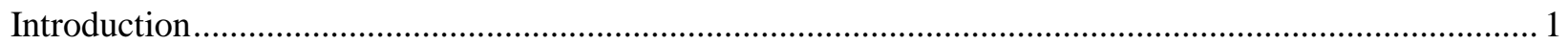

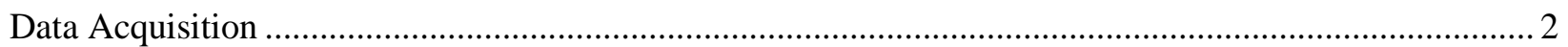

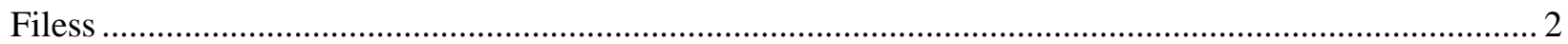

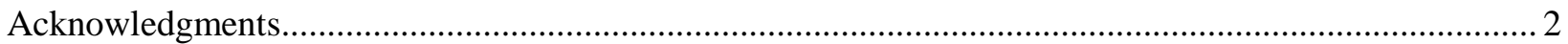

\section{FIGURE}

Figure 1. Location of LiDAR data collection area.............................................................................. 1

\section{APPENDIX}

Appendix A. 2013 AeroMetric, Inc., Acquisition and Processing Report.................................................. 3

Note: This report, including all digital LiDAR data, explanations, and tables, is available in digital format from the DGGS website (www.dggs.alaska.gov) for free download. 

LIDAR DATA FOR UNALAKLEET, ALASKA, COLLECTED OCTOBER 27, 2005

by

Lauren E. Southerland and Nicole E.M. Kinsman

\section{Introduction}

This report is a summary of a LiDAR data collection over the community of Unalakleet, in the Norton Sound region of Alaska (fig. 1). The original data were collected on October 27, 2005 by AeroMetric, Inc., under contract by Rodney P. Kinney and Associates, Inc. The complete, classified LiDAR dataset was purchased by the State of Alaska Division of Geological \& Geophysical Surveys in 2013 in support of coastal vulnerability mapping efforts. For the purposes of open access to LiDAR datasets in coastal regions of Alaska, this collection is being released as a Raw Data File with an open end-user license.

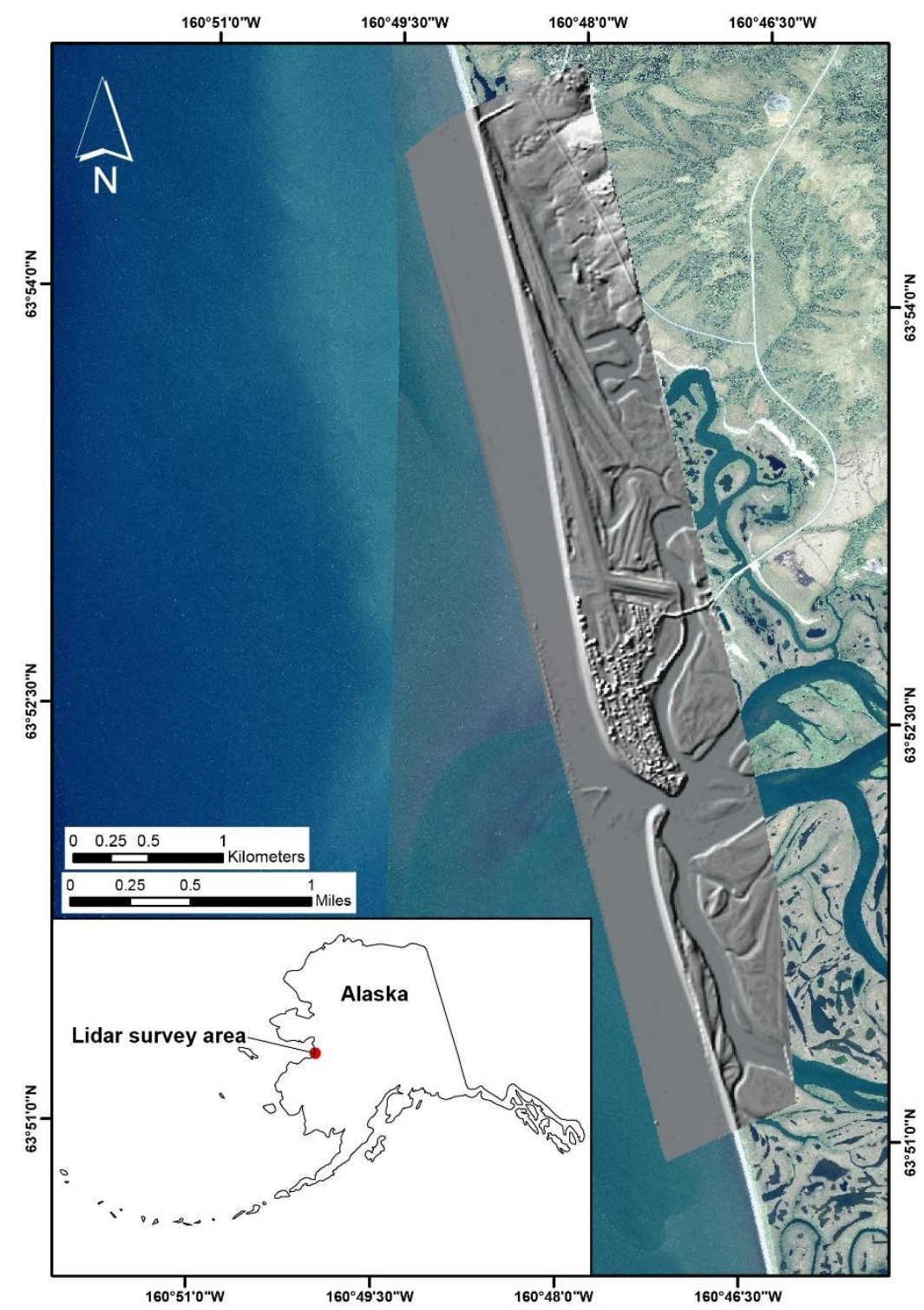

FIGURE 1. Location map of 2005 LiDAR data collection area over the coastal community of Unalakleet, Alaska, and displayed as a hillshaded raster overlain on 2005 IKONOS-2 satellite imagery. 


\section{Data acquisition}

LiDAR data, initially collected on October 27, 2005 and fully post-processed in 2013 by AeroMetric, Inc., comprises a $3.5 \mathrm{mi}^{2}$ coverage over the coastal community of Unalakleet $\left(63^{\circ} 53.31^{\prime} \mathrm{N}, 160^{\circ} 47.95^{\prime} \mathrm{W}\right.$, Unalakleet D4 1:63,360-scale U.S. Geological Survey quadrangle).

The LiDAR dataset for this area was obtained with an average laser pulse rate of $70 \mathrm{kHz}$ under operational conditions designed to achieve a nominal point spacing of $0.74 \mathrm{~m}$. The data were delivered to DGGS with a reported vertical accuracy of $0.11 \mathrm{~m}$ at the 95 percent confidence interval. This confidence value is based on 700+ check points evaluated by AeroMetric, Inc.; a full summary of this vertical accuracy assessment is available in the 2013 delivery report, which can be found on the DGGS website (http://dggs.alaska.gov/pubs/id/27121)

The vertical accuracy of the LiDAR dataset was independently evaluated by DGGS with use of control points ( $\mathrm{n}=8)$ that were collected by DGGS during the course of 2011 fieldwork or publicly available from the National Geodetic Survey (NGS) Online Positioning User Service (OPUS). The standard deviation of the differences between these independent control points and the LiDAR point-cloud data confirmed the vertical accuracy reported by AeroMetric, Inc., in the 2013 delivery report.

The 2013 delivery report also contains an explanation of the point-cloud classification scheme that was applied by AeroMetric, Inc.

\section{Files}

The project files available for download comprise tiled and classified LiDAR point-clouds (LAS 1.1 format), polygons for the tile index, and a polygon that outlines the full LiDAR survey area. These data are projected in UTM Zone 4 (meters) using the NAD83 horizontal and NAVD88 (Geoid09) vertical datums, as outlined in the accompanying metadata. Note: The Acquisition and Processing Report provided by AeroMetric, Inc., incorrectly lists the file format as LAS 1.3.

\section{Acknowledgments}

This publication is funded with qualified outer continental shelf oil and gas revenues by the Coastal Impact Assistance Program, U.S. Fish and Wildlife Service, U.S. Department of the Interior.

The views and conclusions contained in this document are those of the authors and should not be interpreted as representing the opinions or policies of the U.S. Government. Mention of trade names or commercial products does not constitute their endorsement by the U.S. Government. 


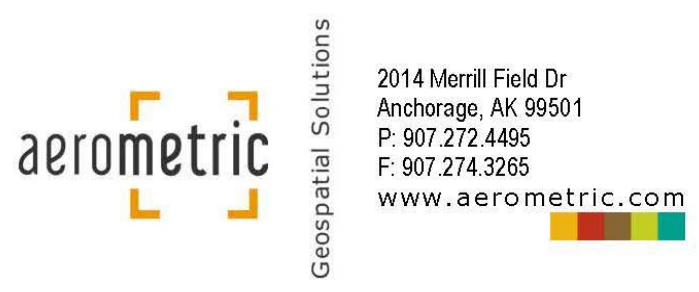

Acquisition and Processing Report For

Alaska Division of Geological \& Geophysical Surveys

3354 College Road

Fairbanks, Alaska 99709

\section{Existing LiDAR Processing - Unalakleet, Alaska}

Prepared by

AERO-METRIC, INC.

2014 Merrill Field Drive

Anchorage, AK 99501

AeroMetric Project No. 6130307 
Table of Contents

\section{Unalakleet Existing LiDAR}

AeroMetric Project No. 6130307

TITLE

SECTION

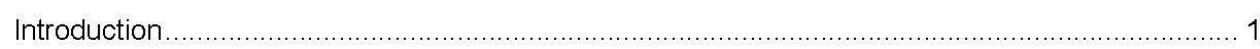

Geodetic Control \& Quality Control Surveys ........................................................................ 2

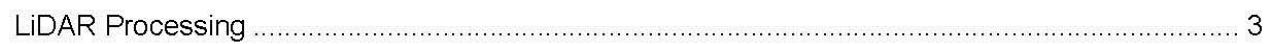

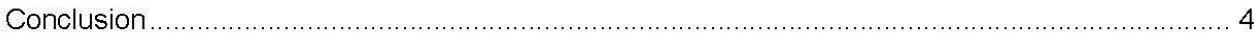

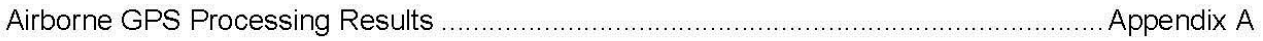




\section{INTRODUCTION}

This report contains a summary of the LiDAR data acquisition and processing in the vicinity of Unalakleet in the Norton Sound region of Alaska. This data was originally acquired in 2005 for contour mapping purposes in Unalakleet as contracted by Rodney P. Kinney and Associates, Inc. (RPKA).

\subsection{Contact Info}

Questions regarding the technical aspects of this report should be addressed to:

AeroMetric, Inc

2014 Merrill Field Dr.

Anchorage, AK 99501

ATTN: Jason Mann (LiDAR Production Manager)

Telephone: 907-272-4495

Email: imann@aerometric.com

\subsection{Purpose}

The Alaska Division of Geological and Geophysical Surveys (DGGS) had a requirement for coastal LiDAR data in the Norton Sound region. Data was to be of sufficient quality to meet an absolute vertical accuracy of no greater than $15 \mathrm{~cm}$.

Aero-Metric, Inc. (AeroMetric) had existing LiDAR data for an area that comprises approximately 3.5 square miles. AeroMetric's Optech ALTM 30 / 70 LiDAR system was used in the 2005 collection of data that was used for this project.

\subsection{Time Period}

Original LiDAR data was acquired on October $27^{\text {th }}, 2005$. Initial airborne and point cloud processing was completed in early 2006 . These data were retrieved from archives, re-evaluated and processed during March and early April of 2013.

\subsection{Project Scope}

The LiDAR data for this project was collected with AeroMetric's Optech 30 / 70 LiDAR systems (Serial Number 03SEN145). Flight planning and acquisition was completed using Optech's ALTMNAV.

The LiDAR collection was planned to achieve a 0.74 meter nominal point spacing throughout the project area. See the following tables for details. 


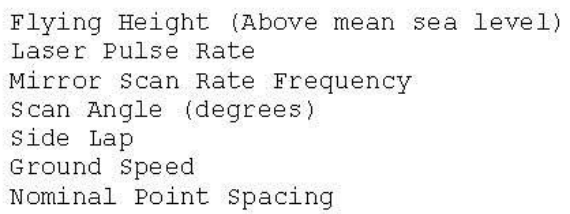

$575 \mathrm{~meters}$
$70 \mathrm{kHz}$
$43 \mathrm{~Hz}$
$23^{\circ}$
$500^{\circ}$
$140 \mathrm{kts}$
$0.74 \mathrm{~m}$

The data was to be calibrated such that all systematic errors were accounted for. The project required bare-earth, vegetation, building, and water classification. Buildings with a roof "footprint" of greater than 400 square feet were to be located and classified.

\subsection{Project Location}

The project area extends North - South approximately 4.5 miles along the Norton Sound coast, covering the town of Unalakleet as well as the mouth of the Unalakleet river.

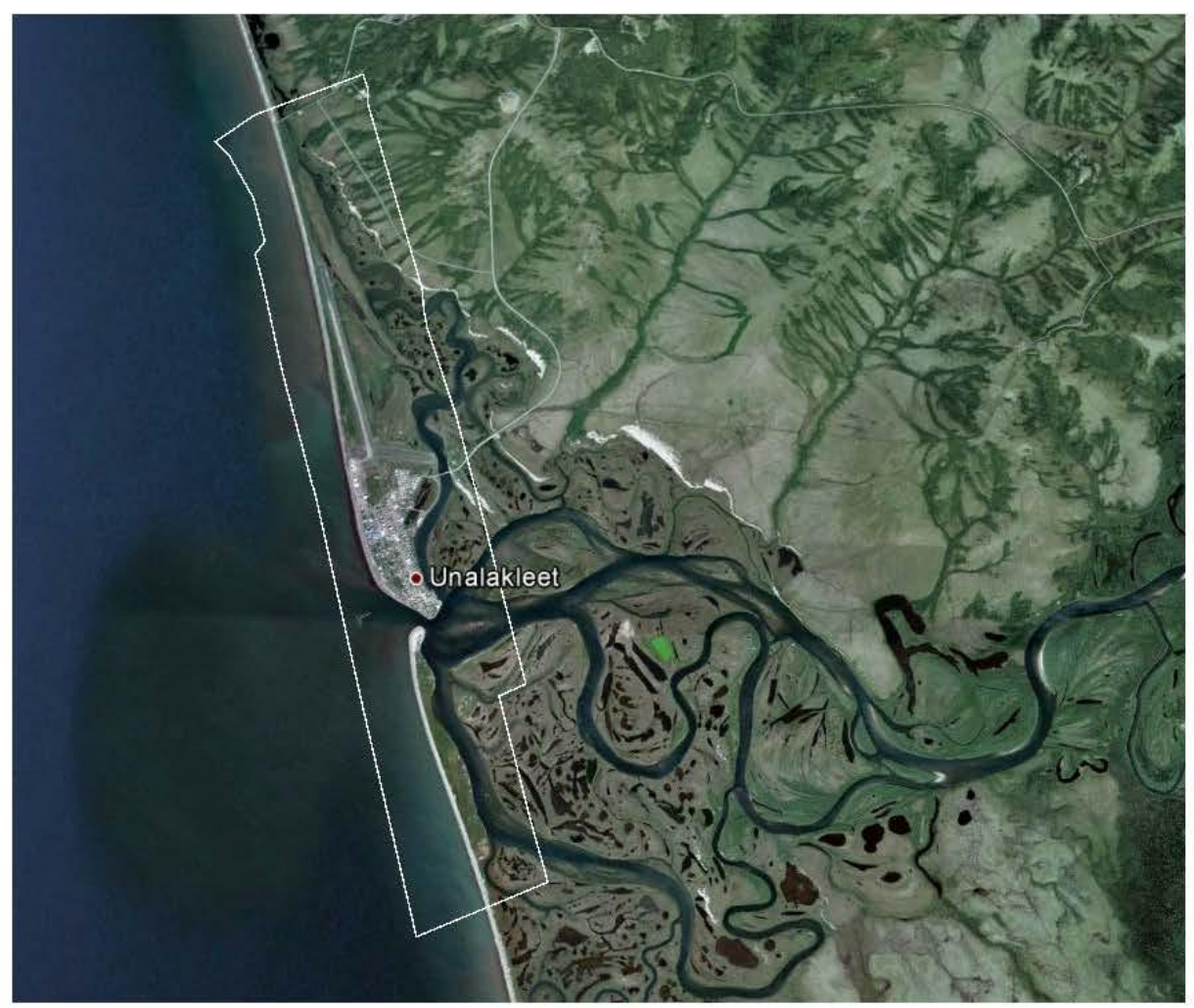

Figure 1.1 - White Outline Approximately Delineates Project Area of Interest (Imagery Source: Google Earth) 


\section{GEODETIC CONTROL \& QUALITY CONTROL SURVEYS}

Control surveys and were completed by RPKA and provided to AeroMetric in early 2006. A portion of these survey activities was dedicated to establishing control points to be occupied by GPS ground stations during LiDAR acquisition. These control positions, shown in the table below, were tied into positions used for 2004 Mapping by the Alaska Department of Commerce, Community, and Economic Development.

\begin{tabular}{|c|c|c|c|c|c|c|c|}
\hline \multicolumn{8}{|c|}{ BASE STATION COORDINATES PROVIDED BY RPKA IN 2006} \\
\hline \multirow[b]{2}{*}{ Control Station } & \multicolumn{3}{|c|}{ Latitude } & \multicolumn{3}{|c|}{ West Longitude } & \multirow{2}{*}{$\begin{array}{c}\text { Ellipsoid } \\
\text { Height }\end{array}$} \\
\hline & Degrees & Minutes & Seconds & Degrees & Minutes & Seconds & \\
\hline UNK1 & 63 & 52 & 58.06133 & 160 & 47 & 51.48847 & 18.929 \\
\hline UNK3 & 63 & 52 & 58.62324 & 160 & 47 & 49.37663 & 19.784 \\
\hline
\end{tabular}

The ellipsoid height values provided to AeroMetric by RPKA in 2006 were reverse calculated using GEOID99 with NGVD29 monument values. NAVD88 elevations were computed for UNK1 using NGS' OPUS from the static GPS data collected during the acquisition of these data. The difference between NGVD29 and NAVD88 (using GEOID09) was computed to be -5.207 meters and was applied to the 2005 LiDAR.

Additionally, RTK checkpoints were collected by RPKA throughout Unalakleet. This survey consisted of several hundred check points spread throughout the project area, exceeding the FGDC Accuracy Test Guidelines minimums. These check points were provided to AeroMetric for use in correcting the LiDAR data for vertical biases and assessing the vertical accuracy of the data.

\section{LIDAR PROCESSING}

\subsection{ABGPS and IMU Processing}

\section{Introduction}

Raw airborne GPS and inertial navigation system (INS) data are acquired during airborne LiDAR collections. AeroMetric utilizes Applanix, Inc. (Applanix) software and hardware for the collection, storage, and processing of these data.

For this project, determination of the sensor trajectory was based on a smoothed combination of differential GPS processing utilizing ground stations and INS data. Operating ground stations in Unalakleet insured a high quality GPS solution as baseline lengths for this project were exceedingly minimal.

\section{Airborne GPS}

The differential GPS processing technique used by Applanix software for achieving the desired accuracy is Kinematic Ambiguity Resolution (KAR). KAR searches for ambiguities and uses a special method to evaluate the relative quality of each intersection (RMS). The quality indicator is used to evaluate the accuracy of the solution for each processing computation. In addition to the quality indicator, the software will compute separation plots between any two solutions, which will ultimately determine the acceptance of the airborne GPS post processing.

Graphical representations of the quality indicator and solution separation for this project are included in this report under Appendix A - Airborne GPS Processing Results. 


\section{Inertial Data}

The post-processing of the INS data is to compute an optimally blended solution of the INS and GPS trajectory data. The Kalman filter-based aided inertial navigation algorithm generates an accurate (in the sense of least-square error) navigation solution that will retain the best characteristics of the processed input data. An example of inertial/GPS sensor blending is the following: inertial data is smooth in the short term. However, a free- inertial navigation solution has errors that grow without bound with time. A GPS navigation solution exhibits short-term noise but has errors that are bounded. This optimally blended navigation solution will retain the best features of both. The resultant processing generates the following data:

- Position: Latitude, Longitude, Altitude

- Velocity: North, East, and Down components

- Attitude: roll, pitch, true heading

- Acceleration: $\quad x, y, z$ components

- Angular rates: $\quad x, y, z$ components

These final data are stored in a smoothed best-estimated trajectory (SBET) file, which is used in the processing and calibration of the point cloud, and has been included in this delivery.

\subsection{LiDAR Point Cloud Processing}

Original raw data was combined with the processed trajectory in 2005 using Optech's REALM software. The resultant swaths were NAD83 UTM Zone 4 LAS1.0 files in meters, with ellipsoid heights. These swaths were generated without scan angle or return fields populated. The points were classified by return number. Using these classifications in combination with the timestamp information, the return fields were populated in March of 2013 using proprietary in-house software.

The LAS files were then imported into GeoCue version 7.0.34.0 (GeoCue). GeoCue was used to generate tiled LAS data referencing NAD83 UTM Zone 4 with Orthometric heights based on GEOID09. Since the point cloud data still lacked scan angle information, these tiles were brought into TerraSolid's TerraScan (TerraScan) where the noisy points along the swath edges were manually re-classified to exclude them from use in the calibration process.

\subsection{LiDAR Calibration}

\section{Calibration Procedures}

AeroMetric routinely performs two types of calibrations on its airborne LiDAR system. The first calibration, system calibration, is performed whenever the LiDAR system is installed in the aircraft. This calibration is performed to define the system parameters affected by the physical misalignment of the system versus aircraft. The second calibration, in-situ calibration, is performed for each mission using that missions data. This calibration is performed to refine the system parameters that are affected by the on site conditions as needed.

\section{System Calibration}

The system calibration is performed by collecting data over a known test site that incorporates a flat surface and a large, flat roofed building. A ground survey is completed to define the flat surface and the building corners. The processed LiDAR data and ground survey data is input into TerraSolid's TerraMatch (TerraMatch) software to determine the systematic errors. The system 
parameters are then corrected according to the determined errors and used in the processing of future LiDAR acquisition missions

\section{In-situ Calibration}

The in-situ calibration is performed as needed using the mission's data. This calibration is performed to refine the system parameters that are affected by the on site conditions. The processed swaths are compared using Terramatch software to determine if any systematic errors are present. Once systematic errors are isolated and accounted for, TerraMatch is used to perform a line-to-line statistical fit to account for any remaining flight or sensor issues.

\subsection{LiDAR Processing}

After the data has been processed and calibrated a relative accuracy assessment is performed an alyzing the flightline to flightline vertical alignment. GeoCue is utilized to create images in dicating elevation differences that provide a visual interpretation of how well flight lines match, and are a useful tool in determining either the success or need to re-evaluate the in-situ calibration procedure.

Areas containing dense vegetation coverage or inundation from water will show a greater elevation offset then is actually present in the ground data. This is due to these regions having a high number of returns from vegetation or non-ground objects and fewer returns from the ground, relative to open ground areas, causing the elevation offset to be exaggerated in areas of heavy vegetation. It is generally understood that flightlines should match tightly in areas of open, moderate terrain, and will not match as well in steeper terrain due to less predictable angles of pulse return

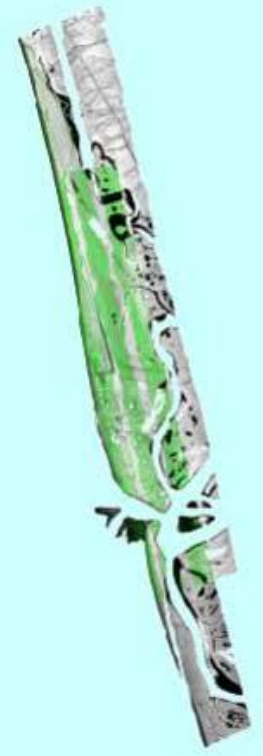

Grcen indicates arcas of ovcrlap with line-to-line $z$-differences of no greater than $7.5 \mathrm{~cm}$.

Figure 3.1 - Project Wide "dZ Ortho" Displaying Differences Between Swaths 
Once both the accuracy between swaths is accepted an automated classification algorithm is performed using TerraScan. This will produce the majority of the bare-earth datasets, as well as the initial building classification. The remainder of the data was classified using manual classification techniques.

The majority of the manual editing involved changing points initially misclassified as ground (class 2) to unclassified (class 1). Erroneous low points, high points, including clouds are classified to class 1 with the withheld bit set. Water bodies were delineated horizontally and classified within TerraScan

\subsection{Vertical Accuracy Assessment}

The LiDAR data was compared with and adjusted to the collected GPS road profiles discussed in section 2 of this report using both TerraScan and in-house statistical analysis tools. This was done to eliminate any vertical biases that may be present within the calibrated LiDAR data set. Once the data was vertically adjusted, the vertical accuracy was computed as discussed in the FGDC's Geospatial Positioning Accuracy Standards, Part 3: National Standard for Spatial Data Accuracy (NSSDA), section 3.2.1.

The final vertical accuracy for this data set is 0.11 meters, at the $95 \%$ confidence interval using the NSSDA definitions. This value is based upon the $700+$ check points that were used in open terrain with moderate slopes. These check point positions, and their differences from the LiDAR data, are included and summarized in the spreadsheet Unalakleet_QA_QC_Results.xIs in the Metadata directory of this delivery.

\subsection{LiDAR Data Delivery}

All deliverables listed below use the following spatial reference per the project specifications:

Horizontal Datum:

Vertical Datum:

Projection:

Measurement Units:
North American Datum 1983

North American Vertical Datum 1988 (GEOID09)

Universal Transverse Mercator (UTM) Zone 4

Meters

Classified Point Cloud Data - Provided in LAS 1.3 format with adjusted GPS timestamps and georeference tags in file headers. Delivery is tiled in accordance with the provided layout and follows the provided classification scheme of:

\begin{tabular}{|l|l|}
\hline Point Class & Classification Description \\
\hline 1 & Processed, but unclassified \\
\hline 2 & Bare-earth ground \\
\hline 3 & Low Vegetation (between 0.10 and 0.50 meters above ground surface) \\
\hline 4 & Medium Vegetation (between 0.5 and 1.0 meters above ground surface) \\
\hline 5 & High Vegetation (between 1.0 and 5.0 meters above ground surface) \\
\hline 6 & Buildings \\
\hline 9 & Water \\
\hline 10 & Ignored Ground (Breakline Proximity) \\
\hline 1 (withheld) & $\begin{array}{l}\text { Erroneous / noise points, including geometrically unreliable points near the } \\
\text { edge of swath }\end{array}$ \\
\hline
\end{tabular}


Unclassified Point Cloud Data - Provided in LAS 1.3 format with adjusted GPS timestamps and georeference tags in file headers; 1 file per swath.

Project Boundary - Provided as ESRI shapefile.

Tile Index - Provided as ESRI shapefile.

Trajectory - Provided in Applanix SBET format, as well as detailed $200 \mathrm{hz}$ ESRI Shapefile containing Position, Elevation, Roll, Pitch, Heading and Timestamp as point records.

Project Metadata - Provided in FGDC compliant XML format, listing all processing procedures and details.

Acquisition, Processing, QA/QC and Survey Reports - Provided as this document, outlining acquisition, processing, and $\mathrm{QC}$ procedures, and all other relevant project information, as well as all other documents referenced herein.

\subsection{Conditions Affecting Final Data}

The project area includes coastal zones subject to changing water levels due to tidal variations. Therefore, water classification was carried out as best as possible given the time of acquisition of these data.

The archived nature of this data gave rise to a handful of specific quality and processing challenges. These were mitigated as best as possible using a variety of industry standard and inhouse data management and processing tools, as discussed throughout this report.

\section{CONCLUSION}

The LiDAR data and derivative products discussed in this report were processed and produced in accordance with provided guidelines and established practices. The accuracy criteria set forward by the client and other Government / Industry standards have been demonstrated to be met throughout this report and its supporting documents. 


\section{APPENDIX A - AIRBORNE GPS PROCESSING RESULTS}

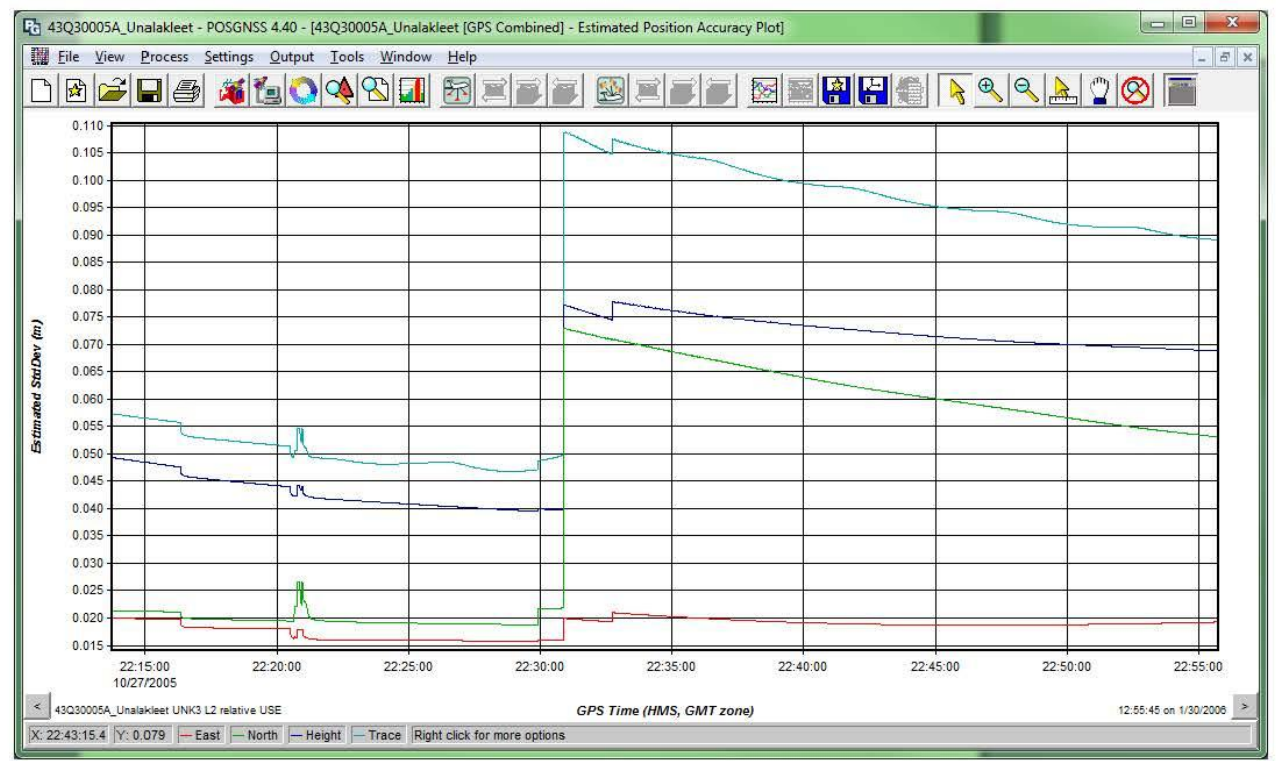

Differential GPS RMSE Plot during time of Unalakleet Acquisition. RMSE $<0.08$ meters

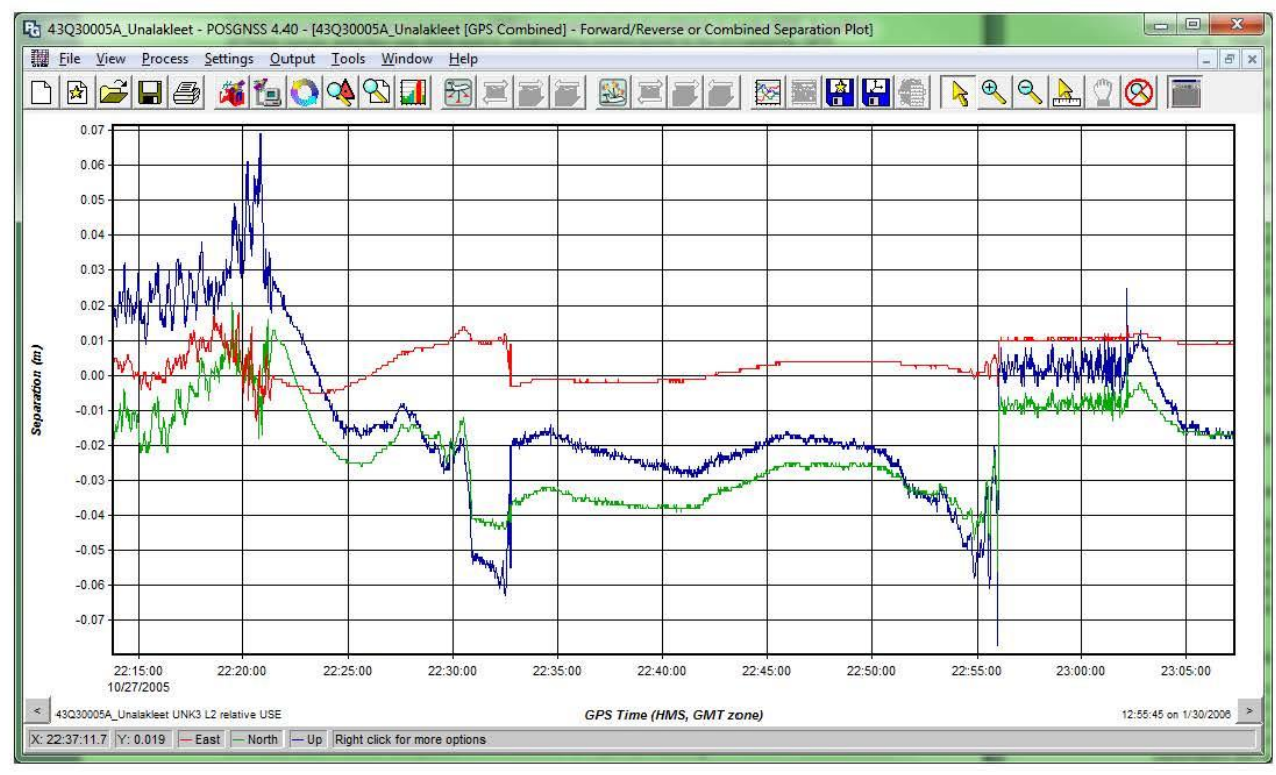

Differential GPS 'Combined Separation' Plot during time of Unalakleet Acquisition. Separation < +/0.07 meters 